\title{
A case study on the consequences of HIV/AIDS within the Caribbean: issues faced by a teenager born with HIV
}

\author{
Emmanuel Janagan Johnson
}

Department of Behavioural Sciences, Faculty of Social Sciences, The University of the West Indies, St. Augustine Campus, Trinidad and Tobago

\begin{abstract}
Children born with HIV in Trinidad and Tobago are surviving until adulthood, especially with free and increased access to antiretroviral therapy. As highly active antiretroviral treatment (HAART) becomes more widely available in the Caribbean, there are an increasing number of babies born with HIV who are surviving to adolescence and adulthood. HIV-positive adolescents face a number of issues shared with other adolescents who are coping with other chronic illnesses. They also face the psychosocial impacts of HIV, which is highly transmittable and still highly stigmatized. However, at present there is little or no support in place to help these children cope with issues they may face as a result of their medical condition. This single case study focuses on the issues and consequences of HIV/ AIDS in the Caribbean, especially as it relates to children and teenagers born with HIV. The findings identified that the subject was well supported by her family and peer support group. The findings also suggest that the problem can only be reduced through continued public education, and policies and laws aimed at reducing stigmatization and discrimination against persons living with HIV and AIDS. The author recommends that HIV prevention strategies for women and girls, especially those of childbearing age, need to be implemented and continuously monitored and evaluated.
\end{abstract}

HIV AIDS Rev 2018; 17, 2: 152-157

DOI: https://doi.org/10.5114/hivar.2018.76379

Key words: HIV/AIDS, anti-retroviral therapy, case study, assessment, risk and resilience.

\section{Introduction}

Highly active antiretroviral treatment (HAART) is becoming more widely available in the Caribbean as there is an increasing number of babies born with HIV who are surviving to adolescence and adulthood. HIV-positive adolescents face a number of issues shared with other adolescents who are coping with other chronic illnesses. However, they also face the psychosocial impacts of HIV, which is highly transmittable and still highly stigmatized. A review by Mellins and Malee [1] found that young people born with

Address for correspondence: Emmanuel Janagan Johnson, Department of Behavioural Sciences, Faculty of Social Sciences, The University of the West Indies, St. Augustine Campus, Trinidad and Tobago,

e-mail: Emmanuel.JanaganJohnson@sta.uwi.edu

HIV are more likely to experience mental health problems although HIV itself may not be the primary contributing factor. Factors such as age, cognitive function, parental health and mental health, and stressful life events have all been found to contribute to negative mental health outcomes in the studies that were reviewed. The review identified gaps in the studies. A limited number of the studies assessed the mental health of adolescents born with HIV, most of which were conducted in the United States, where perinatal infection is almost eliminated.

Article history:

Received: 26.01.2017

Received in revised form: 26.10.2017

Accepted: 22.02.2018

Available online: 21.05 .2018
International Journal of HIV-Related Problem

HIV \& AIDS

R e vi e w 


\section{Literature review}

According to research published by the West Indian Medical Journal [2], perinatal infected adolescents are more likely to have a disrupted family life, mainly due to poverty, inadequate mental and social support, the creation of orphans, and the psychosocial impact of HIV on the child. The study also highlighted the lack of palliative care for these children and that end-of-life issues need to be considered when managing children and adolescents infected by HIV. Although antiretroviral therapy is available and has significantly increased the quality of life for this population, their life expectancy is, nonetheless, reduced; this must be acknowledged and understood by caregivers, health care professionals, and the adolescents themselves. This study is limited in its scope as it is a single case study and should not, therefore, be used as a measure of HIV within the wider Caribbean, as each island is unique.

In a study of 16 young persons aged 13 to 19 diagnosed with HIV, Di Risio et al. [3] found that chronic illnesses such as HIV affects individuals' sense of self and identity, and helps them to anticipate 'interruptions' as a result of the illness. It also has an impact on personal relationships as the individual learns to manage the uncertainty of living with the disease, and the stigma and discrimination as a result of disclosure. Although they had no medical symptoms and saw themselves as healthy, the study found that each individual lived with the awareness that they could become sick. The results of the study also suggested that when the adolescent lived with someone who was also HIV positive and/or provided moral support for therapy, this helped their lives to become normalized.

Patrice-Coy et al. [4] outline several challenges arising from the increasing resources available to manage the health of children infected with HIV at birth. These include maintaining adherence to lifelong therapy, the selection of successive antiretroviral regimens, and the limited availability of antiretroviral drugs designed for children. Additionally, this population has unanticipated needs such as the management of long-term complications of therapy, reproductive and sexual health, and the issue of higher education and career training. The HIV-positive child also has to transition from pediatric care settings to adult HIV care settings and assume responsibility for his or her own care. This factor may lead to a sense of abandonment and result in the young adolescent becoming noncompliant. Therefore, in order to improve the likelihood of positive outcomes of perinatal infected young adults and adolescents, the factors which facilitate and serve as barriers to their health and wellbeing need to be understood and considered when planning their care. A study of adolescents with HIV/AIDS in Jamaica by Christie et al. [5] clearly stated that the HIV-infected patients should be managed according to the clinical manifestations. In another study [4] the authors highlighted that in Carriacou there is an increase in the number of teenage pregnancies which can lead to an increase in the number of persons suffering from HIV and other STDs. The above literature review highlights the need for more studies to be done on the unique needs of the underserved population of young persons born with HIV, from the need for mental health support to the possible contribution this population can make in reducing HIV infections in their communities and palliative care.

\section{Methodology}

Prior to the study, a specific plan was developed to select a person living with HIV. The participant was selected from an agency working for the HIV/AIDS adopting purposeful sampling method. After obtaining permission from the authorities the researcher discussed with the social workers who provided guidance in selecting an appropriate subject for this study. This study was qualitative and open-ended; an interviewer completion format questionnaire was designed to conduct a multidimensional assessment with the participant. Anonymity and confidentiality were emphasized as the participant described herself as a private person. A sit-down, one-on-one interview was conducted with a view to better understand the nature and the context of her living with HIV. The interview took place over the course of two hours to provide space for critical reflection. Critical reflection with a client is integral in empowerment practice. Lee [6] stated that empowerment is a reflexive activity, a process capable of being initiated and sustained only by those who seek power or self-determination. Reflexivity is a process that allows social workers to identify dynamics and trends that exist within the lives of their clients. This process can help the client to identify issues that they are struggling with. It also stresses that the social worker must not lose sight of the ethos of working with the client and not for them [7]. The data were obtained and recorded verbatim and were later compiled and analyzed and an appropriate intervention strategy was formulated.

\section{Compliance with ethical standards}

The ethical protocol was strictly observed by the authors. The researcher kept in mind the sensitive nature of researching an adult affected with HIV. Therefore, Biestek's (1961) principles of confidentiality, acceptance, non-judgmental attitude and client's right to self-determination provided the impetus to facilitate the research process. Emotional issues that came up and had to be addressed urgently were dealt with by utilizing social work skills.

\section{Study}

A fourteen-year old form two student presented to the social worker as a pregnant minor. During the initial interview she disclosed that for as long as she could remember she had been taking medication which made her feel ill. When she questioned her mother about why she had to constantly be on medication she never got a straight answer. 
As she grew older she met a boy of her age, at school, whom she liked. It was not long before she started a relationship. One day, while embroiled in another argument about why she should be using medicine when she felt fine, the client informed her mother that she was going to stop treatment. When her mother realized she was not taking her medication, she informed her that she was born HIV positive hence the reason she needed to continue her medication. On receiving this news the client burst out in tears. She became sexually active with the boy at school and eventually became pregnant as no contraception was used. She still refused to take her medication, even though she now knew the reason she needed to remain adherent.

\section{Social environment}

The client lived with her mother, her elder sister, and her younger brother in a two-bedroom rented apartment. The apartment had electricity and pipe-borne water but toilet and bathroom facilities were outdoors. Her mother was employed as a security officer and had strong support from relatives. Her stepfather died five years ago from AIDS-related complications. Her father died of a heart attack approximately nine months before she was presented to the social worker. He was not infected with HIV. The client's siblings are also uninfected.

\section{Discussion}

\section{Issues affecting the individual}

The client had to deal with the knowledge that she is HIV positive and had been since birth. She felt as if everything she thought to be true about herself and her life was a lie. She thought life was unfair as her siblings were both HIV negative while she was the only one born with the virus. She also had to face stigmatization, both from others and herself. She expressed that she has experienced both stigma and discrimination. Some of "her friends" have suspected that she may be infected with the virus and they make comments such as "if I only get that thing, girl I don't know what I will do" or they may just make "sly jokes" referring to her. Additionally, people who she previously "lived with will be moving differently" such as moving aside to avoid sitting next to her or not touching things that she had previously touched. She began to develop a negative body image, especially now that her body was changing due to pregnancy. Additionally, the client had to face the fact that her non-adherence to treatment meant she could give birth to an HIV-positive baby and if she resumed treatment she may develop drug resistance. The client also had to come to terms with the fact that her mother kept this important secret from her for all her life, once shared by her aunts and grandparents. Further, she was coping with her father's recent demise, changes in her own life, and fear that her mother would soon die like her father. Another issue which would directly affect the client was the way her mother was coping with her own diagnosis and the issues that came with it. The client also needed to have her present to agree to HIV testing and safer sexual practices. Additionally, she needed to decide if and how she would disclose her status to others.

\section{Assessment of risk and resilience}

The assessment showed that living with HIV can prove to be a difficult situation for some individuals. Based on her disclosure pattern, she fears being further stigmatized if she divulges her status to people. Similarly, research has proposed that persons living with HIV live in fear that if their status is revealed they may be rejected by society in general [8]. Hence she has only divulged her status to people who she feels are close to her or close enough to her to show understanding and not stigmatize or discriminate her based on her status. Positively the client is aware of her status and as a result is actively taking her prescribed antiretroviral therapy. This is in keeping with Zastrow [9], who suggests that knowing one's status is important to commence the process of being treated. Before she was diagnosed and had become ill, because she was not aware of her status and as such was not being adequately medicated. Moreover, the client views living with HIV to be lonely and daunting and she expressed that she sometimes "goes home, thinks about things and cries." As such, her support system needs to be explored. Corey et al. [8] contend that people who are diagnosed need to institute support systems which will assist them through their trying times.

The client faced a number of risk factors due to her new diagnosis. Firstly, she felt that given the new knowledge of her status she could not live her dream to become a beautician. Her life now became meaningless and she thought about dropping out of school. As a result her feelings and behaviors at this point in her life could affect her quality of life as she matured. She admitted that she had begun cutting herself as a coping mechanism. She was prone to several risks. The first was her negative body image and her risk of continued risky sexual behavior, which could leave her vulnerable to other sexually transmitted infections, and which could transmit the virus to her partner. Second, her refusal to resume HAART increased her likelihood of suffering a miscarriage or giving birth to an HIV-positive baby as her viral load increased, or the development of drug resistance. Third, she faced the risk of rejection should she disclose her status to her partner or close friends. Fourth, she has the potential to develop a mental health condition such as depression, since she appeared to have unresolved grief over the recent loss of her father which is related to her fear that her mother may soon become ill and die, leaving her an orphan.

The client appeared to face multiple stressors simultaneously, which has decreased her efficacy and her ability to effectively deal with her problems as they arose. All of the above risks could be mitigated if the client received urgent intervention, especially at this critical stage of her development in which she has had to overcome adjustment issues. 
There were a number of factors which potentially supported the client's resilience. Firstly, she had family and financial support. In the Caribbean it is not the norm that persons living with HIV have the support of relatives, but in this case her maternal aunts and grandparents knew of her status and did what they could to support her even before she knew her status. She also had some financial support although she came from a lower income family. She was a candidate for the government's public assistance grant which would decrease the financial burden on the family as a result of the death of her father.

Secondly, the client did well at school and had strong peer relationships with her classmates. She was articulate and possessed good communication skills. She was motivated to remain in school as her favorite subject at school, home economics, built on her love of cooking and her ambition to become a chef. The client's mother also indicated that the client crawled, walked, and talked at the appropriate times during infancy. Ungar [10] describes resilience as the capacity to cope with difficulties, to maintain functioning, to use external challenges as a stimulus for growth and to use social support as a source of strength. Applying the psychodynamic and attachment theories to the present case would empower her to acquire the social skills that she missed in her childhood, which would guard against risk taking behaviors. The psychodynamic approach would deal with her anxiety that was related to her finding out about HIV/AIDS and the consequences that resulted from it. According to Payne [11], both psychodynamic and the attachment approach can help to change her deviant patterns of drug abuse and sexual promiscuity. Through the use of free association or dream analysis techniques, this will help the therapist to identify the repressed feelings or experiences that are locked within her unconscious.

\section{Specific needs}

The client required urgent bereavement counseling, both for the loss of her father and for the loss of her life as she knew it. She needed to rebuild her relationship with her mother after the breakdown of trust. She also needed behavioral change therapy to change the way she dealt with problems as she was harming herself in order to cope.

She needed to be reintegrated into the school system after giving birth. She was at the developmental stage where acceptance by peers was very important to her. The client also needed to be trained to be a good and responsible parent. It was important that she received sex education to prevent another unwanted pregnancy and to protect herself and others from sexually transmitted infections. The client need to be educated about HIV as it directly impacted her health. This knowledge was important in order for her to be able to manage the disease effectively and live a normal life.

\section{Intervention/treatment}

When planning interventions for the client her developmental stage and cognitive processes were considered as well as her interactions with systems within her environment such as her family, school, and community.

According to Erik Erikson's (1959) theory of human development throughout the lifespan, the client was at the stage of Identity versus Identity Confusion. In this stage, the individual gradually becomes independent from parents and places more emphasis on peer relations. The adolescent is preoccupied with self and her changing body image. LeCroy et al. [12] identify this stage as characterized by identity formation, changes in self-esteem, increased sexual awareness, and acceptance or rejection by peers. The young adolescent in the Caribbean is concerned about how they look and how others see them, and some cognitive functions such as problem solving are not fully developed. Adolescence is a stage where persons aspire to discover who they are and what they want to become. When planning social work intervention, the individual's developmental stage should be understood and considered in order to assist the client in obtaining a healthy level of functioning.

Cognitive-behavioral approaches are based on the principle that a person's cognitions are significant in the development and maintenance of emotional and behavioral responses to life situations. Cognitive processes in the form of meanings, judgments, and assumptions about life events are the primary determinants of a person's feelings and actions and therefore either help or hamper the adaptation process [13]. Cognitive-behavioral therapy (CBT) approaches have three core assumptions: cognitive processes and content can be known, our thinking influences the way we respond to environmental cues; and such cognitions can be targeted and eventually changed [14]. Therefore, when cognitions are changed, the individual has increased adaptability and functionality.

The client needed to change the way she thought about and reacted to her HIV diagnosis as the medical condition did not define who she was. The client was educated on information related to HIV and the importance of good nutrition, adherence to HAART, and physical fitness, especially as it related to her pregnancy. She was also educated on the ways she could protect herself and others from infection. The client was assisted in developing tools to manage her new circumstances, adjust her lifestyle, and to express negative and positive emotions. She needed to develop the ability to set realistic personal goals, and to identify and use her available support, especially from her family.

She was encouraged to get in touch with her needs, motivations, and feelings. This included her emotional needs, physical needs, and sexuality. She was also trained in building communication skills. She received bereavement counseling and counseling for her issues regarding the impending death of her father.

The ecological systems approach theorizes that persons interact with systems within the society and influence and are affected by these systems. These systems also interact with and are affected by each other. Therefore, an adequate assessment of a client and possible interventions should consider how individuals and systems influence each other. The satis- 
faction of the individual's needs and the mastery of developmental tasks require enough resources from her environment and positive interactions between the client and her environment [15].

A multidisciplinary approach was needed for successful intervention with the client. She needed HIV therapy, antenatal treatment, and interventions to help her cope with her HIV diagnosis and her pregnancy. She also needed the intervention of her school social worker to aid in reintegrating into the school environment. The client's family was also an integral part of her therapy as they provided her with a support system. She was invited to and agreed to join a support group for young mothers living with HIV, and thus benefitted from peer group support.

The school social worker attached to the client's school was involved as the client needed to eventually make the transition from student to motherhood and then reintegrate into the secondary school system.

\section{Outcomes}

The client was expected to eventually become adherent to HAART and follow nutritional and exercise guidelines given by her dietitian. The goal was for her to manage her medical condition and give birth to a healthy baby who is HIV negative. Her overall health and wellbeing was expected to improve as she developed coping mechanisms to deal with issues and shocks as they occurred in her life. The client's experience with HIV potentially rendered her one of the persons who could provide inspiration and knowledge to other young mothers living with HIV as she shared her experiences and gave encouragement to others in a support group setting. This was expected to strengthen her resilience and reduce the possibility that she would again become non-adherent.

Another expected outcome was that she would get the opportunity to continue her secondary education with the support of her family and abstain from all sexual activity until she was in a position to be more responsible regarding her sexual and reproductive health. The client was also expected to come to terms with issues she faced regarding death and dying: both hers and that of her mother. She would also come to terms with her unresolved issues regarding the deaths of her father and stepfather.

The Caribbean Guidelines for the Care and Treatment of Persons with HIV Infection outlines treatment and procedures for children infected with HIV at birth and provides guidelines for antiretroviral therapy as the children develop. However, these guidelines do not cover the issues associated with transitioning from pediatric care to adolescent and adult care that would arise as the individual grows older. These issues include the individual's ability to manage his or her own care, leaving a familiar health care setting, psychosocial and developmental challenges, and challenges within the health care system [16]. These dynamics should be an integral part of care planning for persons born with HIV and those infected with the virus at a young age.
In Trinidad and Tobago pregnant women are strongly encouraged to get tested for HIV during their pregnancy. However, there is no law or policy mandating that this be done. Prevention of Mother to Child Testing and treatment should be made mandatory in order to reduce the risk of newborn babies being infected with HIV, as the Centers for Disease Control and Prevention [17] in the United States has found that HIV-positive women who take antiretroviral medication during pregnancy can reduce the risk of transmitting the virus to their children to less than one percent, and the instances in which infants are infected are associated with interruptions of care at some point during the pregnancy. Additionally, HIV prevention strategies for women and girls, especially those of childbearing age, need to be implemented and continuously monitored and evaluated. In the event that a baby is born with HIV, intervention with both mother and child should be done at birth or in the early stages of the child's development so that the child can understand his/her medical condition, and adjust and manage the condition as s/he grows older.

\section{Recommendations}

Goals are broad statements about the ideal or hoped for [18]. Within Trinidad and Tobago, the Government has tried to implement certain measures to assist with promoting the well-being of persons living with HIV/AIDS. Some of these are implemented through education, medical institutions and workforce environment. The delivery of these services is also an important factor that contributes to the reduction of such a widespread global issue. Social workers, nurses and clinicians all play a major role in dealing with this issue. Social workers working with HIV/AIDS patients assume multiple roles in order to protect and ensure the safety of the individual. Community outreach activities and house visits are some of the ways that ensure good follow-up. A possible gap that may exist with regard to service delivery is that clients may be scheduled for a counseling session that may be far from the intended need of the service. This can be due to the heavy case load of social workers and the lack of staff to assist. In this case, this gap can cause her to regress into risky behavior because of the lack of counseling sessions available to help with the restructuring of her thoughts, emotions and behaviors. These gaps need to be addressed in order to improve the service given to the clients. A social worker's job is very important and should not be taken for granted. It is seen that there is a need for more social workers to assist with the proper implementation of policies.

\section{Conclusions}

HIV left untreated leads to AIDS. It is transmitted mostly by blood and bodily fluids. In order to help people living with HIV/AIDS, they should be encouraged to live successfully with their disease and always seek new information as this is the primary way for a person with HIV to live their life to the fullest. Being a social worker is not all about forms 
and procedures, but at the heart of it all is the need to help another human being overcome a hardship or difficulty that they are experiencing in their lives. Through education, society is trying to be as "fair" to persons living with HIV/ AIDS as possible, as there is still underlying stigma and discrimination against individuals diagnosed with HIV/AIDS. Although the suggestions are ideals, they do not always happen. The findings identified that the subject was well supported by her family and peer support group and suggest that the discussed problems can only be reduced through continued public education, policies and laws.

\section{Conflict of interest}

The authors declare no potential conflicts of interest with respect to the research, authorship, and/or publication of this article.

\section{References}

1. Mellins CA, Malee KM. Understanding the mental health of youth living with perinatal HIV infection: lessons learned and current challenges. J Int AIDS Soc 2013; 16: 18593.

2. Harrison A, Pierre RB, Palmer P, et al. Clinical manifestations of adolescents with HIV/AIDS in Jamaica. West Indian Medical Journal 2008; 57: 257-264.

3. Di Risio M, Ballantyne PJ, Read SE, Bendayan R. "HIV isn't me...": HIV+ adolescents' experiences in a positive context of support and treatment. AIDS Care 2011; 23: 694-699.

4. Patrice-Coy C, Johnson EJ, Boodram CAS. Sexual behavior of female adolescents on the spread of HIV/AIDS and other STDs in Carriacou. Medicine (Baltimore) 2016; 95: e4800.

5. Christie C, Bain B, Pierre R, et al. HIV/AIDS in women, infants, children and adolescents in Jamaica - A further call to action. West Indian Medical Journal 2001; 50: 258-262.

6. Lee JA. The Empowerment Approach to Social Work Practice: Building the Beloved Community. Columbia University, New York 2001.

7. Jones V, Modeste N, Marshak H, Fox C. The effect of HIV/AIDS education on adolescents in Trinidad and Tobago. ISRN Infectious Diseases 2013; 2013: 691054.

8. Corey G, Corey MS, Callanan P. Issues and Ethics in the Helping Professions. $8^{\text {th }}$ ed. Brooks/Cole, Belmont 2011.

9. Zastrow ChH. The Practice of Social Work. Books/Cole Publishing Company, Singapore 2006.

10. Ungar M. A Deeper, More Social Ecological Social Work Practice. The Social Service Review 2002; 76: 480-497.

11. Payne M. Modern Social Work Theory. Macmillan Press Ltd., London 1997.

12. Ashford JB, LeCroy CW, Lortie KL. Human Behavior in the Social Environment: A Multidimensional Perspective. $3^{\text {rd }}$ ed. Thomson Higher Education, Belmont 2006.

13. Gonzalez-Prendes A, Resco SM. Cognitive-Behavior Therapy. In: Trauma: Contemporary Directions in Theory, Practice, and Research. Ringel S, Brandell J (eds.). Sage Publications, USA 2012.

14. Dobson D, Dobson K. Evidenced-Based Practice of Cognitive-Behavioral Therapy. Guilford, New York 2009.

15. Hepworth D, Rooney R, Rooney GD, et al. Direct Social Work Practice: Theory and Skills. $8^{\text {th }}$ ed. Brooks/Cole, Belmont 2010.

16. Columbia University. Supporting the Transition to Adult Care. Available at: http://files.icap.columbia.edu/files/uploads/Module 13_-_PM_Adolescent.pdf (Accessed: 16 November 2014).

17. Centers for Disease Control and Prevention, 2014. HIV among Pregnant Women, Infants and Children. Available at: http://www. cdc.gov/hiv/risk/gender/pregnantwomen/facts/ (Accessed: 10 November 2016).

18. Bailey KR, Johnson EJ. Internet-based technologies in social work education: experiences, perspectives and use. Caribbean Teaching Scholar Journal 2014; 4: 23-37. 